\title{
Local land subsidence exacerbates inundation hazard to the Kujukuri Plain, Japan
}

\author{
Mao Ouyang, Yuka Ito, and Tomochika Tokunaga \\ Department of Environment Systems, Graduate School of Frontier Sciences, The University of Tokyo, \\ 5-1-5 Kashiwanoha, Kashiwa-shi, Chiba 277-8563, Japan \\ Correspondence: Mao Ouyang (einooumo@hotmail.com) \\ Published: 22 April 2020
}

\begin{abstract}
Flood-inundation hazard maps are generally made based on the anticipated flood patterns under the configurations such as current topography and land use/land cover situations. These maps have not taken into account the possible significance of land subsidence and surface environmental changes. The Kujukuri Plain, Japan, the site of this research, has experienced severe land subsidence due to 2011 Tohoku earthquake. This paper aims to quantify the effects of local land subsidence on flood hazards under heavy rainfalls in the Kujukuri Plain. The high-resolution LiDAR data at two different periods (before and after the Tohoku earthquake) were obtained and used as the input data for the physically-based hydrological model. Through the comparison of simulated inundation areas of the scenarios with the same precipitation pattern but different topographies, the effect of land subsidence was discussed. The maps estimating the inundation areas by only considering rainfalls, i.e., without taking into account the effect of land subsidence, underestimated the inundation areas by around $10 \%$ compared with the ones that accounted for the local land subsidence. The results of this study highlight the importance of taking into account the temporal changes of elevations and other parameters in flood hazard assessments.
\end{abstract}

\section{Introduction}

Flood hazard, which means intensity and severity of floods, affects human society and its economic development (Willner et al., 2018; Winsemius et al., 2013). Globally, $42 \%$ of the land shows an increase in flood hazard under the Representative Concentration Pathways (RCP) 8.5 scenery (van Vuuren et al., 2011; Hirabayashi et al., 2013). Specifically, the low latitude regions in Asia and Africa, show severe inundation hazards with the warmer climate (Hirabayashi et al., 2013; Moss et al., 2010). Earthquake is another natural hazard, which causes significant negative repercussions including soil liquefaction, infrastructure collapse, landslides, tsunamis and land subsidence. Understanding the compound hazards of flood and the earthquake-induced land subsidence would be of great help in preventing a hazard turning to a disaster (Obanawa et al., 2010).

The Kujukuri Plain, Chiba Prefecture, Japan, located nearby Tokyo Metropolitan area, along the Pacific coast (Fig. 1a), was selected as the research site. Figure 1b shows the topographic map in the year 2013, which indicates that the elevations in the south and west parts are higher than those in the central and east coastal areas. Two river systems - Nabaki River, with a catchment area of around $116.5 \mathrm{~km}^{2}$, and Ichinomiya River, with a catchment area of around $203.0 \mathrm{~km}^{2}$, flow through the study area. The tectonic movement due to 2011 Tohoku earthquake has caused severe land subsidence in this area. Ozawa et al. (2011) reported that almost all the land in the study area showed more than $0.1 \mathrm{~m}$ settlements. The main objective of the contribution is to examine the effects of the local land subsidence on the inundation hazards in the coastal basins.

\section{Method}

The dynamic flood model, coupling MIKE HYDRO River (DHI, 2017a) and MIKE SHE (DHI, 2017b), was applied in this research. The model has been widely applied for both academic researches and engineering managements (House et al., 2015; Locatelli et al., 2017). The geological condi- 
(a)

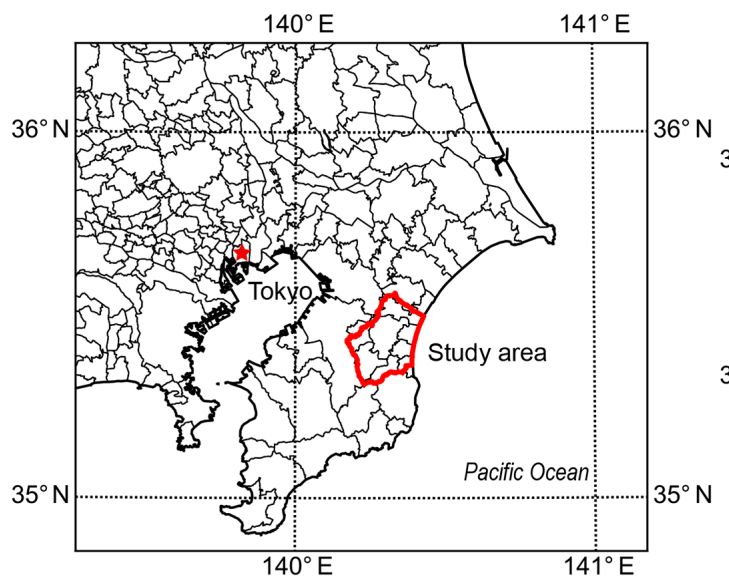

(b)

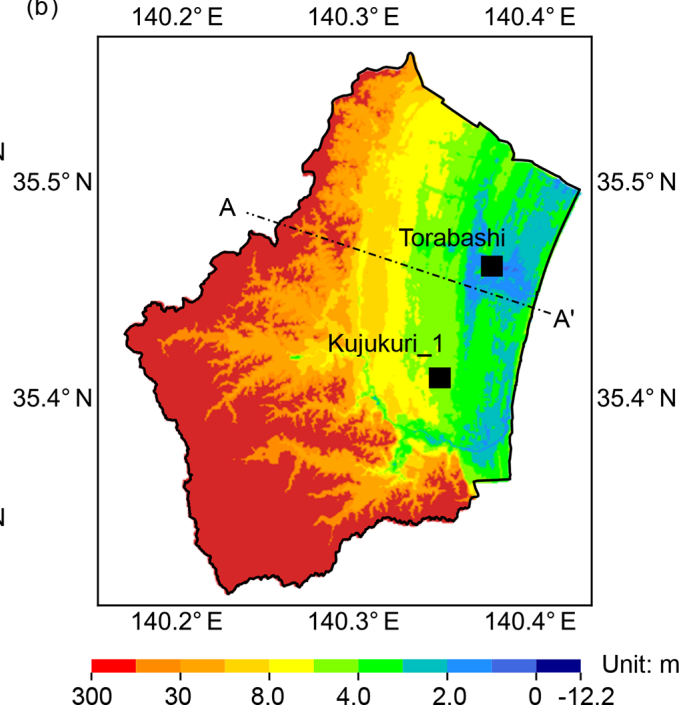

Figure 1. Location and topographic map of the study area. (a) The location of the study area. (b) The topographic map of research site in the year 2013. Torabashi is a river gauging station, where the river water level was used to calibrate the model parameters. Kujukuri_1 is a groundwater observation well, where the validation of the model was performed. The modelled geological cross section along the line $\mathrm{A}-\mathrm{A}^{\prime}$ is shown in Fig. 2a.

Table 1. Scenarios for the calibration, validation and quantification of the dynamic flood model. NA indicates there was no typhoon during the examination period. Total precipitation means the whole rainfall within the examination duration.

\begin{tabular}{lllllrr}
\hline Scenarios & Topography & Simulation period & Examination duration & Typhoon & Total precipitation & Maximum precipitation \\
\hline T13N & 2013 & Jan 2018-Mar 2019 & Feb 2019 & NA & $8.00 \mathrm{~mm}^{2}$ & $5.00 \mathrm{~mm} \mathrm{~h}^{-1}$ \\
T13W & 2013 & Jan-Dec 2013 & 15-16 Oct 2013 & Wipha & $272 \mathrm{~mm}^{-1}$ \\
T04W & 2004 & Jan-Dec 2013 & 15-16 Oct 2013 & Wipha & $272 \mathrm{~mm}^{4}$ & $42.0 \mathrm{~mm} \mathrm{~h}^{-1}$ \\
\hline
\end{tabular}
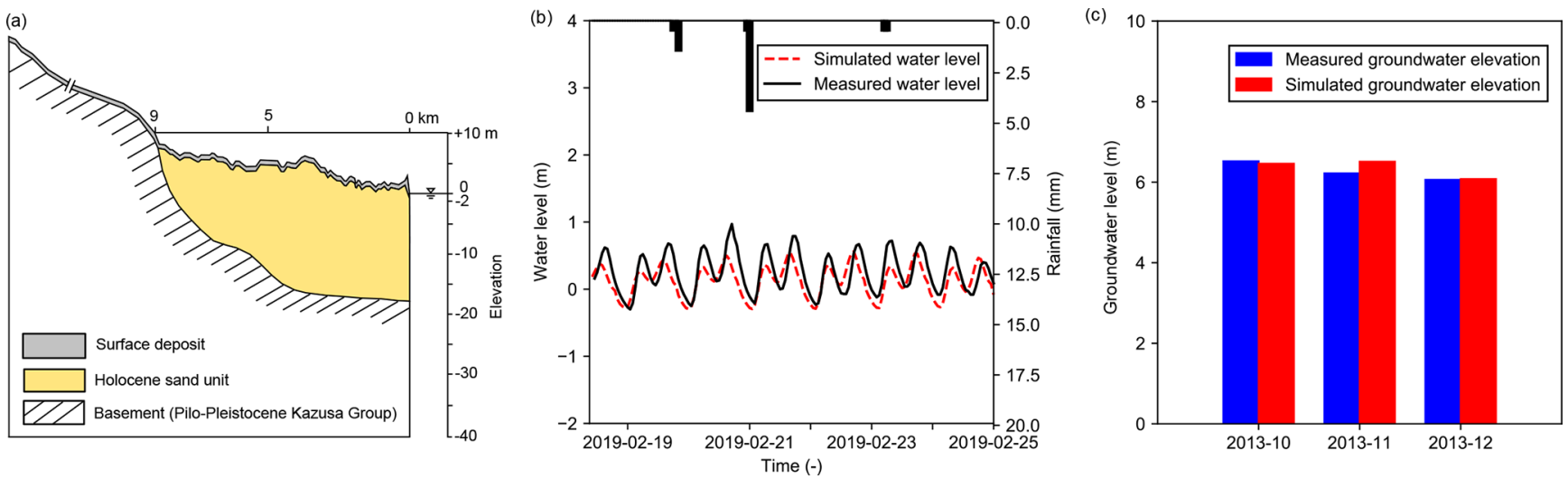

Figure 2. Simplified geological cross section used in this model; calibration and validation of the dynamic flood model. (a) Modelled geological cross section. Location of the cross section $\mathrm{A}-\mathrm{A}^{\prime}$ is shown in Fig. 1b. (b) Calibration of river water levels at the Torabashi gauging station, the location of which is indicated in Fig. 1b. (c) Comparison of groundwater levels in three consecutive months including the examination period at the Kujukuri_1 groundwater observation well, the location of which is also indicated in Fig. 1b. 


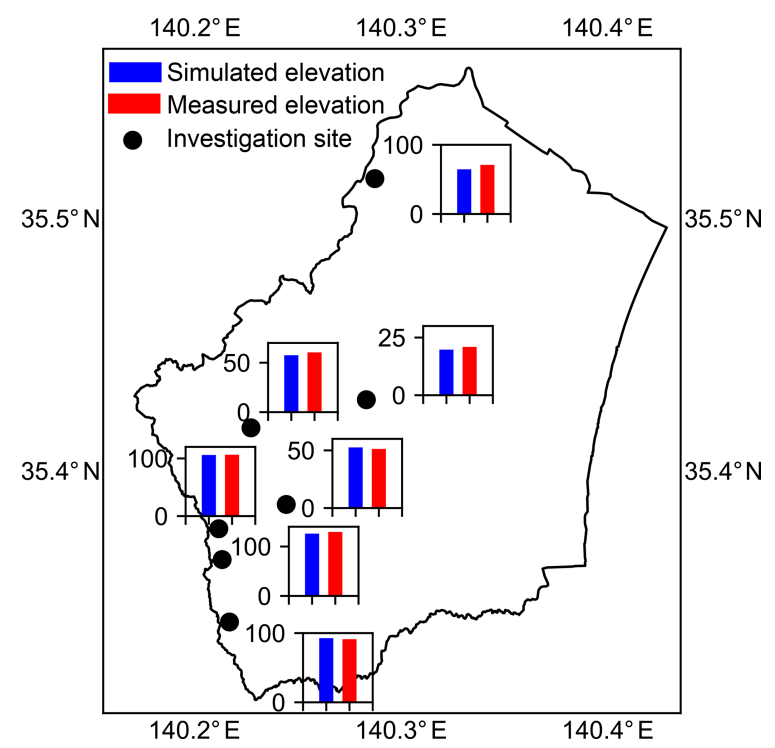

Figure 3. Comparison of simulated and measured spatial distribution of groundwater levels.

tion and underground structure in the model were based on Tamura et al. (2003), as shown in Fig. 2a. Three layers: surface deposits, Holocene unconsolidated sand unit and Pilo-Pleistocene low-permeable Group, were included in the model. The scenarios of this study are listed in Table 1, where the first letter represents the topography, following number indicates the year of input topography, and the final one is the initial letter of the name of typhoon. The case T13N was first applied to calibrate the parameters through the comparison of river water levels. Figure $2 \mathrm{~b}$ shows that the simulated river water level agrees well with the measured water level in the Torabashi gauging station, of which location is shown in Fig. 1c. To further ensure the appropriateness of the parameters used, the typhoon Wipha which attacked the study area from 15 to 16 October 2013, was selected to validate the model (T13W). The goodness of fit by Pearson's chi-square test was 0.986 for the groundwater level (Fig. 2c) in the Kujukuri_1 observation well; the reproducibility of the flooded areas was evaluated by comparing the simulated results and actual flooded areas (Fig. 4). The comparison of spatial distribution of groundwater levels at the mountainous areas is presented in Fig. 3. All the above evidences proved that the parameters are appropriate in this study. Subsequently, the input topography of the case $\mathrm{T} 13 \mathrm{~W}$ was changed to the topography of 2004 (T04W), while keeping the others constant, to quantify the effects of land subsidence on the spatial features of floods.

\section{Results}

The simulated inundation areas of the scenarios T13W and T04W are illustrated in Fig. 4, together with the observa- tions. Around $98 \%$ of the surveyed flooded area can be reproduced by the calculated inundation areas with $\mathrm{T} 13 \mathrm{~W}$ case, which further gained the confidence of the developed dynamic flood model. For the simulated inundation areas in Ichinomiya River watershed, approximately $79 \%$ of simulated flooded areas were actually reported to be flooded.

The inundation areas of both case $\mathrm{T} 13 \mathrm{~W}$ and $\mathrm{T} 04 \mathrm{~W}$ (Fig. 4) showed that the coastal areas, urban areas (central part), and the places along the rivers were most vulnerable to floods. Comparison of these maps elaborated that during the typhoon Wipha, the change of input topographies would alter the spatial patterns of the floods. The calculated inundation areas by case $\mathrm{T} 13 \mathrm{~W}$ was $67.0 \mathrm{~km}^{2}$, while those by case T04W $60.5 \mathrm{~km}^{2}$, indicating additional $6.50 \mathrm{~km}^{2}(9.70 \%)$ of flooded area was somehow related to the land subsidence in the research site.

To spatially quantify the effects of land subsidence on the inundation areas, the difference of the calculated inundation areas between $\mathrm{T} 04 \mathrm{~W}$ and $\mathrm{T} 13 \mathrm{~W}$, i.e., the area flooded by $\mathrm{T} 13 \mathrm{~W}$ but not by $\mathrm{T} 04 \mathrm{~W}$, was obtained and shown in Fig. 5. This figure noted that the land subsidence would exacerbate the inundation areas in the study site. Specifically, in the northern mountainous environment, the inundated locations were exaggerated by the earthquake-induced land subsidence. The Kujukuri plain has also been suffering from continuous land subsidence possibly due to groundwater exploitation, and the next step would tackle the effect of groundwater abstraction-induced land subsidence on the changes of the possible flood pattern and the assessment of future floods.

\section{Conclusions}

We developed a dynamic flood model to quantify the impacts of land subsidence on inundation areas in Kujukuri plain. The results revealed that the earthquake-induced land subsidence would change the spatial distribution of flooded areas. For the examination period in this study, the increase of inundation areas at around $10 \%$ were calculated to be caused by the local land subsidence. Detailed comparison of inundation areas indicated that land subsidence would exacerbate the flood hazards not only in the mountainous environment but also in the urban and coastal zones.

The possible consequence of the increased inundation areas includes salt water intrusion, accelerated coastal erosion, and wetland losses, which may lead to unprecedented socioeconomic impacts (Chen et al., 2015; Ito et al., 2015). This research provided an improved and updated hazard maps for the catchments suffering land subsidence (Erkens and Sutanudjaja, 2015), and information for the mitigation measures (Aichi and Tokunaga, 2015). 


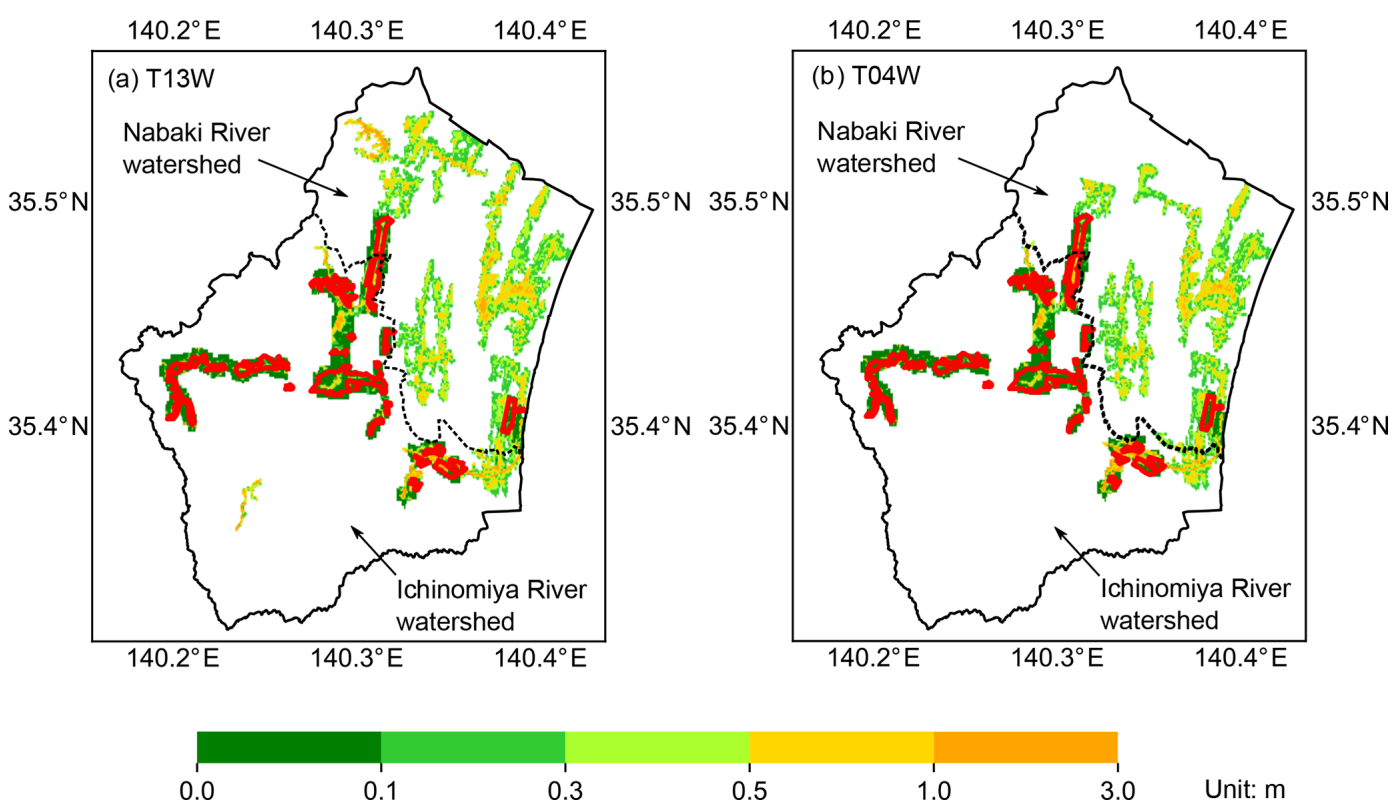

Figure 4. Inundation areas of observation and simulation in both Nabaki and Ichinomiya River watershed. The boundary of the watershed is based on Dutta et al. (2006). The regions surrounded by red lines are the reported inundation areas by Chiba Prefecture (2013) mainly in Ichinomiya River watershed.

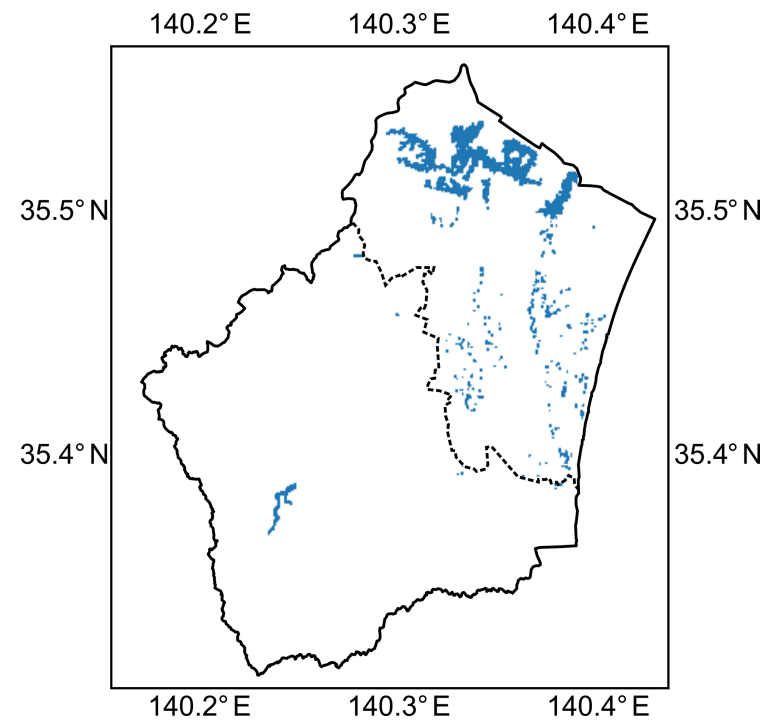

Figure 5. Comparison of the inundation areas by subtracting the inundated locations by $\mathrm{T} 04 \mathrm{~W}$ case from those by $\mathrm{T} 13 \mathrm{~W}$ case.

Data availability. All data needed to evaluate the conclusions in the paper are present in the paper. Additional data related to this paper may be requested from the corresponding author.

Author contributions. MO and TT conceived of the study. YI and MO collated the database. MO performed the modeling and analysis. MO wrote the manuscript. All authors contributed to framing and revising the paper.
Competing interests. The authors declare that they have no conflict of interest.

Special issue statement. This article is part of the special issue "TISOLS: the Tenth International Symposium On Land Subsidence - living with subsidence". It is a result of the Tenth International Symposium on Land Subsidence, Delft, the Netherlands, 17-21 May 2021.

Acknowledgements. We would like to express our sincere gratitude to the Keiyo Natural Gas Association (Japan) for supporting this study.

Financial support. This research has been supported by the Keiyo Natural Gas Association (Japan).

\section{References}

Aichi, M. and Tokunaga, T.: Poroelastic modeling to assess the effect of water injection for land subsidence mitigation, Proc. IAHS, 372, 431-435, https://doi.org/10.5194/piahs-372431-2015, 2015.

Chen, H. L., Ito, Y., Sawamukai, M., Su, T., and Tokunaga, T.: Has land subsidence changed the flood hazard potential? A case example from the Kujukuri Plain, Chiba Prefecture, Japan, Proc. IAHS, 372, 157-161, https://doi.org/10.5194/piahs-372157-2015, 2015. 
Chiba Prefecture: Flooding report in Chiba Prefecture, available at: http://www.pref.chiba.lg.jp/ (last access: 21 February 2020), 2013 (in Japanese).

DHI: MIKE HYDRO River User Guide, DHI Water \& Environment, Hørsholm, Denmark, 2017a.

DHI: MIKE SHE User Manual, Volume 1: User Guide, DHI Water \& Environment, Hørsholm, Denmark, 2017b.

Dutta, D., Herath, S., and Musiake, K.: An application of a flood risk analysis system for impact analysis of a flood control plan in a river basin, Hydrol. Process, 20, 1365-1384, https://doi.org/10.1002/hyp.6092, 2006.

Erkens, G. and Sutanudjaja, E. H.: Towards a global land subsidence map, Proc. IAHS, 372, 83-87, https://doi.org/10.5194/piahs372-83-2015, 2015.

Hirabayashi, Y., Mahendran, R., Koirala, S., Konoshima, L., Yamazaki, D., Watanabe, S., Kim, H., and Kanae, S.: Global flood risk under climate change, Nat. Clim. Change, 3, 816-821, https://doi.org/10.1038/nclimate1911, 2013.

House, A., Thompson, J., Sorensen, J., Roberts, C., and Acreman, M.: Modelling groundwater/surface water interaction in a managed riparian chalk valley wetland, Hydrol. Process., 30, 447462, https://doi.org/10.1002/hyp.10625, 2015.

Ito, Y., Chen, H., Sawamukai, M., Su, T., and Tokunaga, T.: An analysis on the relationship between land subsidence and floods at the Kujukuri Plain in Chiba Prefecture, Japan, Proc. IAHS, 372, 163-167, https://doi.org/10.5194/piahs-372-163-2015, 2015.

Locatelli, L., Ole, M., Mikkelsen, P., Arnbjerg-Nielsen, K., Deletic, A., Roldin, M., and Binning, P.: Hydrologic impact of urbanization with extensive stormwater infiltration, J. Hydrol., 544, 524537, https://doi.org/10.1016/j.jhydrol.2016.11.030, 2017.

Moss, R. H., Edmonds, J. A., Hibbard, K. A., Manning, M. R., Rose, S. K., van Vuuren, D. P., Carter, T. R., Emori, S., Kainuma, M., Kram, T., Meehl, G. A., Mitchell, J. F. B., Nakicenovic, N., Riahi, K., Smith, S. J., Stouffer, R. J., Thomson, A. M., Weyant, J. P., Weyant, J. P., and Wilbanks, T. J.: The next generation of scenarios for climate change research and assessment, Nature, 463, 747-756, https://doi.org/10.1038/nature08823, 2010.
Obanawa, H., Tokunaga, T., Rokugawa, S., Deguchi, T., and Nakamura, T.: Land subsidence at the Kujukuri Plain in Chiba Prefecture, Japan: evaluation and monitoring environmental impacts, Proc. IAHS, 339, 293-298, 2010.

Ozawa, S., Nishimura, T., Suito, H., Kobayashi, T., Tobita, M., and Imakiire, T.: Coseismic and postseismic slip of the 2011 magnitude-9 Tohoku-Oki earthquake, Nature, 475, 373-376, https://doi.org/10.1038/nature10227, 2011.

Tamura, T., Masuda, F., Sakai, T., and Fujiwara, O.: Temporal development of prograding beach-shoreface deposits: the Holocene of Kujukuri coastal plain, eastern Japan, Mar. Geol., 198, 191207, https://doi.org/10.1016/S0025-3227(03)00123-3, 2003.

van Vuuren, D. P., Edmonds, J., Kainuma, M., Thomson, A., Hibbard, K., Hurtt, G. C., Kram, T., Krey, V., Lamarque, J.-F., Masui, T., Meinshausen, M., Nakicenovic, N., Smith, S. J., and Rose, S. K.: The representative concentration pathways: an overview, Climate Change, 109, 5-31, https://doi.org/10.1007/s10584-0110148-z, 2011.

Willner, S. N., Otto, C., and Levermannn, A.: Global economic response to river floods, Nat. Clim. Change, 8, 594-598, https://doi.org/10.1038/s41558-018-0173-2, 2018.

Winsemius, H. C., Van Beek, L. P. H., Jongman, B., Ward, P. J., and Bouwman, A.: A framework for global river flood risk assessments, Hydrol. Earth Syst. Sci., 17, 1871-1892, https://doi.org/10.5194/hess-17-1871-2013, 2013. 